\title{
Maternal HLA Ib Polymorphisms in Pregnancy Allo-Immunization
}

\begin{abstract}
Gry Persson ${ }^{1}$, Christophe Picard ${ }^{2,3}$, Gregory Marin ${ }^{4}$, Cecilie Isgaard ${ }^{1,5}$, Christina Seefeldt Stæhr ${ }^{1,5}$, Nicolas Molinari ${ }^{4}$, Jacques Chiaroni ${ }^{2}$, Morten Lebech ${ }^{6}$, Thomas Vauvert F. Hviid ${ }^{1,5}$ and Julie Di Cristofaro ${ }^{2 *}$

${ }^{1}$ Centre for Immune Regulation and Reproductive Immunology (CIRRI), Department of Clinical Biochemistry, The ReproHealth Research Consortium ZUH, Zealand University Hospital, Roskilde, Denmark, ${ }^{2}$ Aix Marseille Univ, CNRS, EFS, ADES, "Biologie des Groupes Sanguins", Marseille, France, ${ }^{3}$ Immunogenetics Laboratory, Etablissement français du Sang PACA Corse, Marseille, France, ${ }^{4}$ Unité de Recherche Clinique, Biostatistique et Epidémiologie, Département de I'Information Médicale (DIM) Hôpital La Colombière, Montpellier, France, ${ }^{5}$ Department of Clinical Medicine, University of Copenhagen, Copenhagen, Denmark, ${ }^{6}$ Department of Obstetrics and Gynecology, Zealand University Hospital, Roskilde, Denmark
\end{abstract}

OPEN ACCESS

Edited by:

Maria Emilia Solano, University Medical Center Hamburg-

Eppendorf, Germany

Reviewed by: Michael Eikmans, Leiden University Medical Center, Netherlands Gerard Chaouat, INSERM U976 Immunologie, Dermatologie, Oncologie, France

${ }^{*}$ Correspondence: Julie Di Cristofaro julie.dicristofaro@efs.sante.fr

Specialty section: This article was submitted to Immunological Tolerance and Regulation,

a section of the journal

Frontiers in Immunology

Received: 22 January 2021 Accepted: 15 March 2021 Published: 30 March 2021

Citation:

Persson G, Picard C, Marin G, Isgaard C, Stæhr CS, Molinari N, Chiaroni J, Lebech M, Hviid TVF and Di Cristofaro J (2021) Maternal HLA Ib Polymorphisms in Pregnancy Allo-Immunization.

Front. Immunol. 12:657217. doi: 10.3389/fimmu.2021.657217
During pregnancy the formation of alloreactive anti-human leukocyte antigen (HLA) antibodies are a major cause of acute rejection in organ transplantation and of adverse effects in blood transfusion. The purpose of the study was to identify maternal HLA class $\mathrm{lb}$ genetic factors associated with anti-HLA allo-immunization in pregnancy and the degree of tolerance estimated by lgG4 expression. In total, 86 primiparous women with singleton pregnancies were included in the study. Maternal blood samples and umbilical cord samples were collected at delivery. Clinical data were obtained. Maternal blood serum was screened for HLA class I and II antibodies, identification of Donor Specific Antibody (DSA), activation of complement measured by $\mathrm{C} 1 \mathrm{q}$ and IgG4 concentrations. Mothers were genotyped for HLA class Ib (HLA-E, $-F$ and $-G)$. Anti-HLA class I and II antibodies were identified in $24 \%$ of the women. The maternal HLA-E*01:06 allele was significantly associated with a higher fraction of anti-HLA I immunization (20.0\% vs. 4.8\%, $p=0.048)$. The maternal HLA-G 3'-untranslated region UTR4-HLA-G*01:01:01:05 haplotype and the HLA-F*01:03:01 allele were significantly associated with a low anti-HLA I C1q activation (16.7\% vs. 57.1\%, $p=0.028 ; 16.7 \%$ vs. 50.0\%, $p=0.046$; respectively). Both HLA-G and $H L A-F^{\star} 01: 03: 01$ showed significantly higher levels of IgG4 compared with the other haplotypes. The results support an association of certain HLA class Ib alleles with alloimmunization during pregnancy. Further studies are needed to elucidate the roles of HLA$E^{\star}$ 01:06, HLA-F*01:03 and HLA-G UTR4 in reducing the risk for allo-immunization.

Keywords: HLA class Ib, anti-HLA alloimmunization, IgG4, tolerance, pregnancy

\section{INTRODUCTION}

Alloreactive anti-human leukocyte antigen (HLA) antibodies formed during pregnancy are a major cause of acute rejection in organ transplantation and of adverse effects in blood transfusion, such as febrile non-hemolytic transfusion reactions, immunological platelet refractoriness or transfusionrelated acute lung injury (TRALI) $(1,2)$. 
Sir Peter Medawar was among the first to recognize the immunological paradox of pregnancy. The current study is in line with this important scientific theme by investigating a role of maternal HLA class Ib polymorphisms in pregnancy allo-immunization.

Studies on pregnancy-induced alloimmunization have shown that 18 to $74 \%$ of women with a history of pregnancy have antiHLA alloantibodies. The discrepancy between studies may be due to screening differences, both in method sensitivity and the sampling time after delivery, as HLA antibodies may persist or become gradually undetectable over time (1-5). The level of antiHLA antibodies increases with the number of pregnancies and the number of children delivered (1-5). Biological and genetic factors have been associated with pregnancy-induced anti-HLA alloimmunization, however, the process remains poorly understood.

In pregnancy, immunization seems to be driven by special mechanisms. It is hypothesized that among decidual antigen presenting cell (APC) populations (classical macrophages, classical mature dendritic cells (DC), immature DC and myeloid DC), specialized APCs present fetal antigens to the maternal immune system. However, the exact mechanisms that induce a state of tolerance to fetal antigens are unclear (6). Various immunoglobulins (Igs) can play an important role in regulating the pregnancy process and maintaining tolerance to the fetus (7). The average relative levels of IgGs and IgMs in placentas are slightly higher and lower, respectively, than in healthy individuals (7). Considering IgGs, Lowe et al. (2013) suggested that the distribution of anti-HLA IgG subclasses (IgG1-IgG4) varied according to the sensitizing event, i.e. graft, transfusion or pregnancy $(8,9)$. IgG4, whose altered Fc domain reduces antibody-dependent cell-mediated cytotoxicity, complement-dependent cytotoxicity, clearance of antigens and phagocytosis (10), may protect the fetus that harbors paternal antigens from the mother's effector immune mechanisms by competing for antigen and $\mathrm{Fc}$ binding with the other IgG subclasses $(11,12)$. The relevance of IgG4 as an immune tolerance marker is, however, challenged in a transplant context. Lowe et al. found that HLA-DQ specificity and IgG4 were associated with chronic kidney graft failure (8), whereas Lobashevsky et al. reported that IgG2/IgG4 donor specific antibodies (DSA) were associated with antibody-mediated rejection (AMR)-free transplants (13).

Other molecules such as the HLA Ib molecules (HLA-G, HLA-E and HLA-F) also play a major role in inducing tolerance during pregnancy (14). HLA-G, HLA-E and HLA-F are expressed at the materno-fetal interface, whereas trophoblast lacks all other classical class I antigens except HLA-C $(15,16)$. Their tolerogenic properties confer a peculiar interest in comprehension of the alloimmunization process during pregnancy.

HLA-G interacts with the inhibitory receptors Ig-like transcript 2 (ILT2), ILT4 and the killer cell immunoglobulinlike receptor (KIR) 2DL4, expressed by a wide range of immune cells including monocytes, T cells, B cells and NK cells (17-20). Reduced HLA-G expression is associated with pregnancy complications (21). Different HLA-G alleles have been associated both to the HLA-G expression level (22-26) and a better tolerance in pregnancy (27-30). A previous study on immunization in pregnancy suggested that the $H L A$ $G^{\star}$ 01:01:01:04 allele is protective against anti-HLA class II immunization (31).

HLA-E regulates NK cell function through the C-type lectin receptor CD94 combined NKG2 sub-units expressed on NK and CD8+ $\alpha \beta$ T cells $(32,33)$. HLA-E is expressed by placental and trophoblast cells but also by immune effectors (34). HLA-E mRNA expression is similar in peripheral blood mononuclear cells (PBMCs) from homozygous $H L A-E^{\star} 01: 01$ or $H L A-E^{\star} 01: 03$ individuals (35). Conversely, HLA-E ${ }^{\star} 01: 03$ membrane-bound expression is higher when compared to $\mathrm{HLA}^{\star} \mathrm{E}^{\star} 01: 01$; furthermore, HLA-E membrane-bound expression depends on the affinity for HLA Ia peptides and appears to be related to cell activation (34). Increased frequency of homozygosity for HLA$E^{\star} 01: 01$ in Egyptian women with recurrent miscarriage was reported (15).

HLA-F participates in immune regulation in pregnancy, infections, autoimmunity and cancer especially through the KIR3DS1 receptor $(16,36-38)$. Like HLA-E, HLA-F membrane-bound expression is associated with a state of activation (39). Little data are available concerning associations between specific HLA-F alleles and the expression of HLA-F or clinical outcome. $H L A-F^{\star}$ 01:01:02 was associated with higher mRNA expression (40), and $H L A-F^{\star} 01: 03$ was associated with lower Hepatitis B virus DNA level in Tunisian patients with hepatitis B virus chronic infection (41).

The main goal of the current study was to identify maternal HLA $I b$ genetic factors associated with anti-HLA allo-immunization in pregnancy and the level of tolerance estimated by IgG4 expression. To circumvent problems with the aspect of multigravity immunization, this study includes primaparous women with no history of pregnancy complications or blood transfusion.

\section{MATERIAL AND METHODS}

\section{Patients, Data and Sample Collection}

The study was designed together with the Centre for Immune Regulation and Reproductive Immunology (Zealand University Hospital and the University of Copenhagen, Denmark). The recruitment of the pregnant women was completed during their last visit at the birth clinic at the Department of Obstetrics and Gynaecology, Zealand University Hospital, Roskilde, Denmark. All subjects gave written informed consent for participation in the study prior to sample collection. The protocol has been approved by the local ethics committee for Region Zealand (National Committee on Health Research Ethics; No. SJ591).

Eighty-six women were included in the study. Maternal blood samples and umbilical cord samples were collected at delivery. Collected data included maternal age, fetal gender, pregnancy and transfusion history. All included women were primigravidae and had singleton pregnancies. None of the women had any recorded previous or present interruption of pregnancy or dead infant. No women experienced pregnancy complications or showed any history of transfusion. 
Whole blood collected in serum tubes (BD, \#367624) was left to coagulate at room temperature (RT) and maternal serum was obtained by centrifugation (RT, $2000 \mathrm{x} \mathrm{g}, 10 \mathrm{~min}$ ). Serum was stored at $-80^{\circ} \mathrm{C}$. Genomic DNA was extracted from EDTA blood (BD, \# 365900) of the mother and cord using the QIAsymphony DSP DNA Midi Kit for $1000 \mu$ l samples using a QIASymphony instrument (QIAGEN, Hilden, Germany). Genomic DNA concentration was measured using DropSense 96 and DropQuant (Trinean, Gentbrugge, Belgium) before being stored at $-20^{\circ} \mathrm{C}$. All samples were shipped on dry ice to Etablissement Français du Sang PACA Corse, Marseille, France, for further analysis.

\section{Maternal Anti-HLA Alloimunization}

Maternal serum from whole blood collected at delivery was screened for detection of HLA class I and class II antibodies, identification of Donor Specific Antibody (DSA) and the ability of antibody to bind and activate complement as measured by C1q. Sera were screened for anti-HLA antibodies with Luminex LABScreen Mixed (SPA-Screen Solid phase screen, One Lambda Inc, West Hills, CA, USA). Sera that were positive in class I and class II SPA-Screen assays (normalized background (NBG) ratio $>3$ for any class I multi-antigen bead and NBG ratio $>4.5$ for any class II multi-antigen bead) was further tested to identify antibody specificity by LABScreen Single Antigen (SAB, One Lambda Inc, West Hills, CA, USA) according to the manufacturer's instructions. Sera positive in SAB (MFI > 500) were further tested to identify complement-fixing DSA using a C1q Screen assay (One Lambda Inc, West Hills, CA, USA) according to the manufacturer's instructions (MFI > 1,000). HLA FUSION 2.0 software (One Lambda) on the LABScan100 flow cytometer (Luminex Inc.) was used for interpretation.

Identification of mismatched inherited paternal HLA antigens (IPA) was based on two-field resolution HLA typing of both mother and child. The HLA-A, $-B,-C,-D R B 1$ and $-D Q B 1$ genes from both maternal and child genomic DNA were sequenced by Next Generation Sequencing (NGS) using a 5 loci kit V2 (H23 holotype HLA 96/5 config A\&CE V2 from Omixon Biocomputing KFT, Budapest, Hungary).

\section{Maternal IgG4 Dosage}

Measurement of IgG4 was performed in duplicate on maternal serum samples using the ELISA for quantitative detection of human IgG4 (\#BMS2095, Life Technologies, Waltham, Massachusetts, U.S.) according to the manufacturer's protocol. Detection threshold was $10 \mathrm{IU} / \mathrm{mL}$.

\section{Maternal HLA Ib Typing}

Mothers were typed for $H L A-E,-F$ and $-G$. Furthermore, the $H L A-G$ haplotype based on the regulatory regions was also sequenced. The HLA $I b$ genes were sequenced by NGS (4244). The HLA-E gene was sequenced from position -257 to +3072 (primer sequences were TCATCTCTGTGGGCTACGTG and TCAGACCCCCAGAATCTCAC); the $H L A-F$ gene was sequenced from position -266 to +3249 (GTGGCTCTC AAGGGCTCAG and GCAACAACCAAAGCATCGTA); the $H L A-G$ gene was sequenced from position -1983 to +3447 (primer sequences: AGGAGCTGACACAGGAGGAA and
CAGCTGAGCAGTGACCACAT). Amplification was performed using the Long Range PCR Kit (Qiagen). PCR fragments were sequenced using an NGS platform (MiSeq, Illumina, San Diego, California, U.S.).

HLA-E, $-F$ and - G NGS data were analyzed through PolyPheMe software (Xegen, Gemenos, France) based on the HLA sequences listed in the official IMGT/HLA database (45). High-resolution typing of $H L A-G$ regulatory regions (H1 to H74) was performed according to all polymorphic variations from position -1983 to -1 in the 5'UTR and from +2540 to +3447 in the 3'UTR. The HLA-G haplotype identification numbers were coded as previously described $(44,46)$. Allelic, UTR and haplotype frequencies were estimated using PHASE and an EM algorithm implemented in the Gene[Rate] computer tools (47).

\section{Data Interpretation and Statistical Analysis}

Quantitative data are given in median and range [min-max] or mean and standard deviation (SD). Associations between antiHLA antibody, DSA, C1q activation, IgG4 expression and HLA $I b$ genetic polymorphism were tested with logistic regression, when the predicted variable was categorical, and general linear regression when the predicted variable was quantitative.

Univariate analyses were performed on each of the following variables or features: anti-HLA antibody, DSA, C1q activation according to HLA Ib genetic polymorphisms and IgG4 expression. The False Discovery Rate correction for multiplicity was applied; no power analysis was performed. Variables with corrected pvalues below 0.15 in univariate analysis were further investigated in multivariate analysis. Results were considered significant if $\mathrm{p}$ values were below 0.05 after stepwise type selection.

Analysis of IgG4 expression according to HLA Ib genetic polymorphisms was performed by Wilcoxon-Mann-Whitney test. Results were considered significant if $\mathrm{p}$-values were below 0.05 .

Results of association analyses with quantitative variables were expressed as estimates and standard errors (Std error), whereas results of association analyses with qualitative variables were expressed as odd ratios (OR) and 95\% confidence intervals (CI 95\%).

\section{RESULTS}

\section{Population Characteristics}

The median age of the mothers was 28 years (range 18-40 years), median gestational age was 281 days (range 236-299 days) and median birth weight was $3638 \mathrm{~g}$ (range 1730-5030 g).

Twenty-one women (24\%) had anti-HLA class I antibodies, 21 women (24\%) had anti-class II antibodies; 10 (11\%) women had both. Fifteen of the women (17\%) had anti-HLA class I antibodies that activated complement, and 4 (5\%) women had anti-HLA class II antibodies that activated complement (Table 1). Women with anti-HLA antibodies directed against IPA, defined as donor Specific Antibodies (DSA), were considered for analysis (21\% for anti-class I antibodies and $21 \%$ for anti-class II antibodies). All women but two had measurable IgG4 in their serum (mean: $870 \mathrm{IU} / \mathrm{mL}$; range: $0-3450 \mathrm{IU} / \mathrm{mL}$ ). The results are presented in Table $\mathbf{1 .}$ 
TABLE 1 | Characteristics of participants and sera.

\begin{tabular}{lc}
\hline Number of Women & $\mathbf{8 6}$ \\
\hline Age (years) (median and range) & $28[18-40]$ \\
Gestational age (days) (median and range) & $281[236-299]$ \\
Birth weight (gram) (median and range) & $3638[1730-5030]$ \\
Fetal gender (n Female/Male) & $35 / 51$ \\
HLA class I antibody (n) (percentage positive) & $21(24 \%)$ \\
HLA class II antibody (n) (percentage positive) & $21(24 \%)$ \\
HLA class I and class II antibody (n) (percentage positive) & $10(11 \%)$ \\
DSA HLA class I antibody (n) (percentage positive) & $18(21 \%)$ \\
DSA HLA class II antibody (n) (percentage positive) & $18(21 \%)$ \\
HLA class I antibody with complement activation (n) & $15(17 \%)$ \\
(percentage positive) & $4(5 \%)$ \\
HLA class II antibody with complement activation (n) & \\
(percentage positive) & $895( \pm 829)$ \\
lgG4 (IU/ml) (mean and SD) & \\
\hline
\end{tabular}

\section{Maternal $E^{\star 01: 06}$ Allele Association With a Higher Frequency of} Anti-HLA I Immunization

The HLA-E ${ }^{\star} 01: 06$ allele was associated with anti-HLA I antibody in multivariate analysis ( $20 \%$ vs. $4.8 \%$; $\mathrm{p}=0.048$; OR $=5.0$, CI [1.024.6]; Table 2). HLA Ib polymorphisms and IgG4 with corrected p-values below 0.15 in univariate analyses are shown in Table 2.

\section{Maternal HLA-G UTR4-G*01:01:01:05 Haplotype and $F^{*}$ 01:03:01 Allele Association With Lower Frequency of Anti-HLA I C1q Activation and Higher IgG4 Expression}

The HLA-G UTR4 haplotype, in linkage disequilibrium (LD) with $G^{\star 01: 01: 01: 05 ~(44), ~ a n d ~ t h e ~ H L A-F ~ a l l e l e ~} F^{\star} 01: 03: 01$ were both associated with absence of HLA class I antibody complement activation (respectively $\mathrm{p}=0.028$; $\mathrm{OR}=0.1, \mathrm{CI}$ [0.01-0.8]; and $\mathrm{p}=$ 0.046; OR $=0.1$, CI [0.01-0.97]; Table 3) and higher IgG4 expression (Wilcoxon-Mann-Whitney, respectively $\mathrm{p}=0.03$, $1200.2( \pm 975.9) \mathrm{IU} / \mathrm{mL}$ vs. $671.5( \pm 552.7) \mathrm{IU} / \mathrm{mL}$; and $\mathrm{p}=$ $0.05,1165.6$ ( \pm 959.5) IU/mL vs. 681.8 ( \pm 549.4) IU/mL, Table 4).

\section{DISCUSSION}

Peter Medawar's pregnancy paradox from 1953 was the first to propose an explanation for maternal acceptance of the semiallogenic fetus during pregnancy. Although much knowledge has been added to the field since then, pregnancy remains a model to study the development of allogenic tolerance and anti-HLA alloantibodies. Anti-HLA alloantibodies induced by pregnancy are of importance because of clinical adverse effects of pretransplantation donor-specific antibodies (DSA) in transfusion and in the graft. Their prevalence is reported with wide ranges probably because of technical differences. When anti-HLA alloantibodies may become undetectable, additional markers of alloimmunization would help to prevent clinical adverse effects.

The expression of HLA class Ib molecules is well described for the establishment of immune tolerance in pregnancy $(22,48)$. HLA-G and HLA-E expression are described to be associated with genetic polymorphisms, whereas little data are available regarding HLA-F $(14,38)$.

We aimed to identify maternal HLA $I b$ genetic markers for allo-immunization during pregnancy and the level of tolerance estimated by IgG4 expression. IgG4 expression may be associated with IPA tolerance in pregnancy, possibly by competing with fetus antigens without maternal immune cell activation $(8,11,12)$. IgG4 antibody subclass may be an illustration of how the maternal immune systems promote tolerance to foreign paternal antigens.

The current study included 86 primigravidae women for which genomic DNA, sera and cord blood were available. Sera were collected at delivery. Maternal anti-HLA antibodies were screened and their ability to activate complement was analyzed. Mothers were genotyped for HLA-G, HLA-E and $H L A-F$, as well as analyzed for the $H L A-G$ regulatory region haplotype. IgG4 concentrations were measured in the maternal sera.

Anti-HLA class I and class II antibodies were identified in $24 \%$ of the women, respectively, of which $17 \%$ and $5 \%$ presented antiHLA class I and class II antibodies that activated complement.

We showed that maternal $E^{\star} 01: 06$ allele was associated with a higher percentage of anti-HLA class I immunization in multivariate analysis. This allele is virtually present only in Europeans and Europeans descents and could not be explored for its expression or association with clinical issues. $H L A-E^{\star} 01: 06$ displays $H L A-E^{\ngtr} 01: 03$ specific variation and a non-synonymous mutation at position $+1857(49,50)$.

We found that the maternal HLA-G UTR4 haplotype and the $F^{\star}$ 01:03:01 allele were both associated with lower anti-HLA I complement activation and higher IgG4 expression. Both results are consistent with and support that both alleles are associated with harmless antibodies (i.e. absence of $\mathrm{C} 1 \mathrm{q}$ activation and $\mathrm{IgG} 4$ subclass) and with an immune response maintained under control. HLA-G UTR4 was associated with a shorter time-to-pregnancy in couples

TABLE 2 | HLA class I antibody according to HLA Ib polymorphisms. All samples were included in the analysis, missing genetic data led to the exclusion of the concerned sample from analysis.

\begin{tabular}{|c|c|c|c|}
\hline & Presence & Absence & OR $(95 \% \mathrm{Cl})\left({ }^{\Delta}\right.$ Univariable; ${ }^{\dagger}$ Multivariable) \\
\hline$\left.E^{\star 01: 06 ~(8.4 \% ; ~} n=7 / 83\right)$ & $20.0 \%(n=4 / 20)$ & $4.8 \%(n=3 / 63)$ & $5.0(1.0-24.6) ; p=0.048^{\dagger}$ \\
\hline HLA-G HO2 (15.1\%; n=13/86) & $28.6 \%(n=6 / 21)$ & $10.8 \%(n=7 / 65)$ & $3.3(1.0-11.3) ; p=0.056^{\Delta}$ \\
\hline HLA-G HO4 (18.6\%; $n=16 / 86)$ & $4.8 \%(n=1 / 21)$ & $23.1 \%(n=15 / 65)$ & $0.2(0.1-1.3) ; p=0.093^{\Delta}$ \\
\hline HLA-G H21 (3.5\%; $n=3 / 86)$ & $9.5 \%(n=2 / 21)$ & $1.5 \%(n=1 / 65)$ & $6.7(0.6-78.4) ; p=0.128^{\Delta}$ \\
\hline $\operatorname{lgG} 4(\mathrm{IU} / \mathrm{mL})$ & $592.7( \pm 583.1)$ & $986.7( \pm 823.2)$ & 0.9 (0.8-1.0); $p=0.07^{\Delta}$ \\
\hline
\end{tabular}

No multiple imputation was used (Logistic Regression). The HLA-G haplotype identification numbers (HLA-G H02, H04, H21) were coded as previously described (44, 46). HLA-G H02 and H04 are associated with UTR4 and HLA-G H21 is associated with UTR5. 
TABLE 3 | HLA I antibody complement activation according to HLA Ib polymorphisms.

\begin{tabular}{lccc}
\hline & Activation & No activation & OR (95\% Cl) ${ }^{\Delta}$ Univariable; ${ }^{\dagger}$ Multivariable) \\
\hline$F^{\star} 01: 03: 0127.8 \%(n=5 / 18)$ & $16.7 \%(n=2 / 12)$ & $50.0 \%(n=3 / 6)$ & $0.1(0.01-0.97) ; p=0.046^{\Delta}$ \\
HLA-G UTR4 31.6\% $(n=6 / 19)$ & $16.7 \%(n=2 / 12)$ & $57.1 \%(n=4 / 7)$ & $0.1(0.01-0.8) ; p=0.028^{\dagger}$
\end{tabular}

Samples with a HLA I antibody were included in the analysis $(n=21)$, missing genetic data led to the exclusion of the concerned sample from analysis. No multiple imputation was used (Logistic Regression).

TABLE 4 | lgG4 expression (Mean ( \pm SD), IU/mL) according to HLA Ib genetic polymorphisms (Wilcoxon-Mann-Whitney test).

\begin{tabular}{|c|c|c|c|}
\hline & Presence & Absence & P-value \\
\hline HLA-G UTR4 & $1200.2( \pm 975.9)$ & $671.5( \pm 552.7)$ & 0.03 \\
\hline$F^{\star 01: 03: 01 ~}$ & $1165.6( \pm 959.5)$ & $681.8( \pm 549.4)$ & 0.05 \\
\hline
\end{tabular}

undergoing infertility treatment (51) and was found more frequent in healthy individuals than in asthmatic patients (44). Concerning HLA-F, in silico analysis reported equivalent mRNA expression in $F^{\star} 01: 03$ and $F^{\star}$ 01:01:01 (40). However, HLA-F expression seems to be driven also by cell interaction and activation. Although HLA$\mathrm{F}^{\star} 01: 03$ displays a polymorphism ( $\mathrm{p} .251 \mathrm{~S}>\mathrm{P}$ ) outside the peptide groove, Ho et al. showed that $\mathrm{F}^{\star} 01: 03$ binds and presents different peptides than $\mathrm{F}^{\star} 01: 01$ and $\mathrm{F}^{\star}$ 01:02 (52). Biological consequences of this feature remain to be explored.

No HLA $I b$ genetic polymorphism or IgG4 expression was significantly associated with anti-HLA II immunization, suggesting that anti-HLA I and anti-HLA II immunization may be driven by different factors, as previously suggested (31). We could not investigate previous published data on the protective role of H03-UTR6-HLA-G ${ }^{*}$ 1:01:01:04 on anti-HLA II immunization during pregnancy (31) as this haplotype was not observed in the cohort under study.

In conclusion, our results support an association of HLA Ib alleles with allo-immunization during pregnancy. Moreover, this study suggests that specific $H L A I b$ alleles are associated with different anti HLA class I antibody properties. HLA Ib molecules are ligands for immune cell inhibitory receptors. B cells require a co-stimulatory signal for maturation, affinity maturation and proper class switching. ILT2 expressed by B cells has high affinity for HLA-G. Interaction of ILT2 ${ }^{+}$B cells with HLA-G has been shown to inhibit their proliferation, antibody production, dampen migration of germinal center B cells as well promoting a shift from Th1 to Th2 response by reducing secreted IFN- $\gamma$ and IL-2, while increasing IL-4 and IL-10 production (53). Interestingly, a xenograft mice model injected with HLA-G ${ }^{+}$xenogeneic cells had reduced levels of anti-xenograft antibodies (53). Regulatory B cells are characterized by IL-10 production, and IgG4 expression has been shown to be confined to this subset of B cells (54), thus specific HLA

\section{REFERENCES}

1. Triulzi DJ, Kleinman S, Kakaiya RM, Busch MP, Norris PJ, Steele WR, et al. The effect of previous pregnancy and transfusion on HLA alloimmunization in blood donors: implications for a transfusion-related acute lung injury risk reduction strategy. Transfusion (2009) 49(9):1825-35. doi: 10.1111/j.15372995.2009.02206.x
$I b$ alleles, associated to differential quantitative or qualitative expression, may modify these ligand-receptor interactions and the course of immune cells response to foreign antigens.

Association of an allo-immunization directed against the fetus without activation of immune effector-cells would be in line with the concept of acquired immunological tolerance in a pregnancy context.

\section{DATA AVAILABILITY STATEMENT}

The raw data supporting the conclusions of this article will be made available by the authors, without undue reservation.

\section{ETHICS STATEMENT}

The studies involving human participants were reviewed and approved by local ethics committee for Region Zealand, National Committee on Health Research Ethics; No. SJ591. The patients/ participants provided their written informed consent to participate in this study.

\section{AUTHOR CONTRIBUTIONS}

All authors listed have made a substantial, direct, and intellectual contribution to the work and approved it for publication.

\section{FUNDING}

This study was funded by Etablissement Français du Sang (APR16) and by the ReproHealth Research Consortium Zealand University Hospital.

2. Eder AF, Benjamin RJ. TRALI risk reduction: donor and component management strategies. J Clin Apheresis (2009) 24(3):122-9. doi: 10.1002/ jca.20198

3. De Clippel D, Baeten M, Torfs A, Emonds MP, Feys HB, Compernolle V, et al. Screening for HLA antibodies in plateletpheresis donors with a history of transfusion or pregnancy. Transfusion (2014) 54(12):3036-42. doi: 10.1111/ $\operatorname{trf} .12727$ 
4. Powers A, Stowell CP, Dzik WH, Saidman SL, Lee H, Makar RS. Testing only donors with a prior history of pregnancy or transfusion is a logical and costeffective transfusion-related acute lung injury prevention strategy. Transfusion (2008) 48(12):2549-58. doi: 10.1111/j.1537-2995.2008.01902.x

5. Masson E, Vidal C, Deschamps M, Bongain S, Thevenin C, Dupont I, et al. Incidence and risk factors of anti-HLA immunization after pregnancy. Hum Immunol (2013) 74(8):946-51. doi: 10.1016/j.humimm.2013.04.025

6. Kammerer U. Antigen-presenting cells in the decidua. Chem Immunol Allergy (2005) 89:96-104. doi: 10.1159/000087951

7. Lekchnov EA, Sedykh SE, Dmitrenok PS, Buneva VN, Nevinsky GA. Human placenta: relative content of antibodies of different classes and subclasses (IgG1-IgG4) containing lambda- and kappa-light chains and chimeric lambda-kappa-immunoglobulins. Int Immunol (2015) 27(6):297-306. doi: 10.1093/intimm/dxv003

8. Lowe D, Higgins R, Zehnder D, Briggs DC. Significant IgG subclass heterogeneity in HLA-specific antibodies: Implications for pathogenicity, prognosis, and the rejection response. Hum Immunol (2013) 74(5):666-72. doi: 10.1016/j.humimm.2013.01.008

9. Malan Borel I, Gentile T, Angelucci J, Pividori J, Guala MC, Binaghi RA, et al. IgG asymmetric molecules with antipaternal activity isolated from sera and placenta of pregnant human. J Reprod Immunol (1991) 20(2):129-40. doi: 10.1016/0165-0378(91)90029-P

10. Davies AM, Sutton BJ. Human IgG4: a structural perspective. Immunol Rev (2015) 268(1):139-59. doi: 10.1111/imr.12349

11. Gu J, Lei Y, Huang Y, Zhao Y, Li J, Huang T, et al. Fab fragment glycosylated IgG may play a central role in placental immune evasion. Hum Reprod (2015) 30(2):380-91. doi: 10.1093/humrep/deu323

12. Gutierrez G, Gentile T, Miranda S, Margni RA. Asymmetric antibodies: a protective arm in pregnancy. Chem Immunol Allergy (2005) 89:158-68. doi: $10.1159 / 000087964$

13. Lobashevsky A, Rosner K, Goggins W, Higgins N. Subtypes of immunoglobulin (Ig)-G antibodies against donor class II HLA and crossmatch results in three kidney transplant candidates. Transplant Immunol (2010) 23(1-2):81-5. doi: 10.1016/j.trim.2010.03.003

14. Persson G, Melsted WN, Nilsson LL, Hviid TVF. HLA class Ib in pregnancy and pregnancy-related disorders. Immunogenetics (2017) 69(8-9):581-95. doi: 10.1007/s00251-017-0988-4

15. Mosaad YM, Abdel-Dayem Y, El-Deek BS, El-Sherbini SM. Association between HLA-E ${ }^{*} 0101$ homozygosity and recurrent miscarriage in Egyptian women. Scandinavian J Immunol (2011) 74(2):205-9. doi: 10.1111/j.13653083.2011.02559.x

16. Lin A, Yan WH. The Emerging Roles of Human Leukocyte Antigen-F in Immune Modulation and Viral Infection. Front Immunol (2019) 10:964. doi: 10.3389/fimmu.2019.00964

17. Colonna M, Samaridis J, Cella M, Angman L, Allen RL, O'Callaghan CA, et al. Human myelomonocytic cells express an inhibitory receptor for classical and nonclassical MHC class I molecules. J Immunol (1998) 160(7):3096-100.

18. Rajagopalan S, Long EO. A human histocompatibility leukocyte antigen (HLA)-G-specific receptor expressed on all natural killer cells. J Exp Med (1999) 189(7):1093-100. doi: 10.1084/jem.189.7.1093

19. Carosella ED, Rouas-Freiss N, Tronik-Le Roux D, Moreau P, LeMaoult J. HLA-G: An Immune Checkpoint Molecule. Adv Immunol (2015) 127:33-144. doi: 10.1016/bs.ai.2015.04.001

20. Shiroishi M, Kuroki K, Rasubala L, Tsumoto K, Kumagai I, Kurimoto E, et al. Structural basis for recognition of the nonclassical MHC molecule HLA-G by the leukocyte Ig-like receptor B2 (LILRB2/LIR2/ILT4/CD85d). Proc Natl Acad Sci USA (2006) 103(44):16412-7. doi: 10.1073/pnas.0605228103

21. Lynge Nilsson L, Djurisic S, Hviid TV. Controlling the Immunological Crosstalk during Conception and Pregnancy: HLA-G in Reproduction. Front Immunol (2014) 5:198. doi: 10.3389/fimmu.2014.00198

22. Rebmann V, da Silva Nardi F, Wagner B, Horn PA. HLA-G as a Tolerogenic Molecule in Transplantation and Pregnancy. J Immunol Res (2014) 2014:297073. doi: 10.1155/2014/297073

23. Moreau P, Flajollet S, Carosella ED. Non-classical transcriptional regulation of HLA-G: an update. J Cell Mol Med (2009) 13:2973-89. doi: 10.1111/j.15824934.2009.00800.x. England.

24. Svendsen SG, Hantash BM, Zhao L, Faber C, Bzorek M, Nissen MH, et al. The expression and functional activity of membrane-bound human leukocyte
antigen-G1 are influenced by the 3 '-untranslated region. Hum Immunol (2013) 74(7):818-27. doi: 10.1016/j.humimm.2013.03.003

25. Carlini F, Traore K, Cherouat N, Roubertoux P, Buhler S, Cortey M, et al. HLA-G UTR haplotype conservation in the Malian population: association with soluble HLA-G. PloS One (2013) 8(12):e82517. doi: 10.1371/ journal.pone.0082517

26. Di Cristofaro J, El Moujally D, Agnel A, Mazieres S, Cortey M, Basire A, et al. HLA-G haplotype structure shows good conservation between different populations and good correlation with high, normal and low soluble HLAG expression. Hum Immunol (2013) 74(2):203-6. doi: 10.1016/ j.humimm.2012.10.027

27. Moreau P, Contu L, Alba F, Lai S, Simoes R, Orru S, et al. HLA-G gene polymorphism in human placentas: possible association of $\mathrm{G}^{\star} 0106$ allele. Biol Reprod (2008) 79(3):459-67. doi: 10.1095/biolreprod.108.068874

28. Tan CY, Ho JF, Chong YS, Loganath A, Chan YH, Ravichandran J, et al. Paternal contribution of HLA-G ${ }^{*} 0106$ significantly increases risk for preeclampsia in multigravid pregnancies. Mol Hum Reprod (2008) 14(5):317-24. doi: 10.1093/molehr/gan013

29. Aldrich CL, Stephenson MD, Karrison T, Odem RR, Branch DW, Scott JR, et al. HLA-G genotypes and pregnancy outcome in couples with unexplained recurrent miscarriage. Mol Hum Reprod (2001) 7(12):1167-72. doi: 10.1093/ molehr/7.12.1167

30. Vargas RG, Sarturi PR, Mattar SB, Bompeixe EP, Silva Jdos S, Pirri A, et al. Association of HLA-G alleles and 3' UTR 14 bp haplotypes with recurrent miscarriage in Brazilian couples. Hum Immunol (2011) 72(6):479-85. doi: 10.1016/j.humimm.2011.02.011

31. Slimane M, Picard C, Chiaroni J, Loundou A, Paganini J, Tiberghien P, et al. Maternal HLA-G*01:01:01:04 protects from anti-HLA-class II immunization in pregnant women. Hum Immunol (2019) 80(2):120-5. doi: 10.1016/ j.humimm.2018.11.003

32. Allan DS, Lepin EJ, Braud VM, O'Callaghan CA, McMichael AJ. Tetrameric complexes of HLA-E, HLA-F, and HLA-G. J Immunol Methods (2002) 268 (1):43-50. doi: 10.1016/S0022-1759(02)00199-0

33. Pratheek BM, Nayak TK, Sahoo SS, Mohanty PK, Chattopadhyay S, Chakraborty NG, et al. Mammalian non-classical major histocompatibility complex I and its receptors: Important contexts of gene, evolution, and immunity. Indian J Hum Genet (2014) 20(2):129-41. doi: 10.4103/0971-6866.142855

34. Morandi F, Pistoia V. Interactions between HLA-G and HLA-E in Physiological and Pathological Conditions. Front Immunol (2014) 5:394. doi: 10.3389/fimmu.2014.00394

35. Lauterbach N, Wieten L, Popeijus HE, Vanderlocht J, van Zon PM, Voorter CE, et al. Peptide-induced HLA-E expression in human PBMCs is dependent on peptide sequence and the HLA-E genotype. Tissue Antigens (2015) 85 (4):242-51. doi: 10.1111/tan.12525

36. Burian A, Wang KL, Finton KA, Lee N, Ishitani A, Strong RK, et al. HLA-F and MHC-I Open Conformers Bind Natural Killer Cell Ig-Like Receptor KIR3DS1. Plos One (2016) 11(9):e0163297. doi: 10.1371/ journal.pone. 0163297

37. Garcia-Beltran WF, Holzemer A, Martrus G, Chung AW, Pacheco Y, Simoneau CR, et al. Open conformers of HLA-F are high-affinity ligands of the activating NK-cell receptor KIR3DS1. Nat Immunol (2016) 17(9):106774. doi: $10.1038 /$ ni. 3513

38. Langkilde CH, Nilsson LL, Jorgensen N, Funck T, Perin TL, Hornstrup MB, et al. Variation in the HLA-F gene locus with functional impact is associated with pregnancy success and time-to-pregnancy after fertility treatment. Hum Reprod (2020) 35(3):705-17. doi: 10.1093/humrep/dez276

39. Lee N, Ishitani A, Geraghty DE. HLA-F is a surface marker on activated lymphocytes. Eur J Immunol (2010) 40(8):2308-18. doi: 10.1002/eji.201040348

40. Buttura RV, Ramalho J, Lima THA, Donadi EA, Veiga-Castelli LC, MendesJunior CT, et al. HLA-F displays highly divergent and frequent haplotype lineages associated with different mRNA expression levels. Hum Immunol (2019) 80(2):112-9. doi: 10.1016/j.humimm.2018.10.016

41. Laaribi AB, Hannachi N, Ben Yahia H, Marzouk M, Mehri A, Belhadj M, et al. Human leukocyte antigen (HLA-F) polymorphism is associated with chronic HBV infection. 3 Biotech (2018) 8(1):49. doi: 10.1007/s13205-017-1079-9

42. Paganini J, Ramdane A, Gouret P, Chiaroni J, Di Cristofaro J. Validation of new HLA-F alleles assigned by next-generation sequencing. Hla (2019) 93(23):131-2. doi: $10.1111 / \tan .13455$ 
43. Carlini F, Ferreira V, Buhler S, Tous A, Eliaou JF, Rene C, et al. Association of HLA-A and Non-Classical HLA Class I Alleles. PloS One (2016) 11(10): e0163570. doi: 10.1371/journal.pone.0163570

44. Ribeyre C, Carlini F, Rene C, Jordier F, Picard C, Chiaroni J, et al. HLA-G Haplotypes Are Differentially Associated with Asthmatic Features. Front Immunol (2018) 9:278. doi: 10.3389/fimmu.2018.00278

45. Robinson J, Barker DJ, Georgiou X, Cooper MA, Flicek P, Marsh SGE. IPDIMGT/HLA Database. Nucleic Acids Res (2020) 48(D1):D948-D55. doi: $10.1093 / \mathrm{nar} / \mathrm{gkz} 950$

46. Nilsson LL, Djurisic S, Andersen AM, Melbye M, Bjerre D, Ferrero-Miliani L, et al. Distribution of HLA-G extended haplotypes and one HLA-E polymorphism in a large-scale study of mother-child dyads with and without severe preeclampsia and eclampsia. Hla (2016) 88(4):172-86. doi: $10.1111 / \tan .12871$

47. Nunes JM. Using uniformat and gene[rate] to analyse data with ambiguities in population genetics. Figshare. Evol Bioinform Online (2014) 11(Suppl 2):1926. doi: 10.6084/m9.figshare. 984299

48. Hviid TV. HLA-G in human reproduction: aspects of genetics, function and pregnancy complications. Hum Reprod (2006) 12(3):209-32. doi: 10.1093/ humupd/dmi048

49. Paganini J, Abi-Rached L, Gouret P, Pontarotti P, Chiaroni J, Di Cristofaro J. HLAIb worldwide genetic diversity: New HLA-H alleles and haplotype structure description. Mol Immunol (2019) 112:40-50. doi: 10.1016/ j.molimm.2019.04.017

50. Veiga-Castelli LC, Felicio LP, Georg RC, Castelli EC, Donadi EA. A nonsynonymous mutation at HLA-E defines the new $\mathrm{E}^{\star} 01: 06$ allele in Brazilian individuals. Tissue Antigens (2013) 82(3):216-7. doi: 10.1111/ $\tan .12177$
51. Nilsson LL, Scheike T, Langkilde CH, Jorgensen N, Hornstrup MB, Perin TL, et al. Examining extended human leukocyte antigen-G and HLA-F haplotypes: the HLA-G UTR-4 haplotype is associated with shorter time to pregnancy in an infertility treatment setting when both female and male partners are carriers. Fertil Steril (2020) 114(3):628-39. doi: 10.1016/ j.fertnstert.2020.04.052

52. Ho GT, Heinen FJ, Blasczyk R, Pich A, Bade-Doeding C. HLA-F AlleleSpecific Peptide Restriction Represents an Exceptional Proteomic Footprint. Int J Mol Sci (2019) 20(22):5572. doi: 10.3390/ijms20225572

53. Naji A, Menier C, Morandi F, Agaugue S, Maki G, Ferretti E, et al. Binding of HLA-G to ITIM-bearing Ig-like transcript 2 receptor suppresses B cell responses. J Immunol (2014) 192(4):1536-46. doi: 10.4049/jimmunol.1300438

54. van de Veen W, Stanic B, Yaman G, Wawrzyniak M, Sollner S, Akdis DG, et al. IgG4 production is confined to human IL-10-producing regulatory B cells that suppress antigen-specific immune responses. J Allergy Clin Immunol (2013) 131(4):1204-12. doi: 10.1016/j.jaci.2013.01.014

Conflict of Interest: The authors declare that the research was conducted in the absence of any commercial or financial relationships that could be construed as a potential conflict of interest.

Copyright $(\odot 2021$ Persson, Picard, Marin, Isgaard, Stcehr, Molinari, Chiaroni, Lebech, Hviid and Di Cristofaro. This is an open-access article distributed under the terms of the Creative Commons Attribution License (CC BY). The use, distribution or reproduction in other forums is permitted, provided the original author(s) and the copyright owner(s) are credited and that the original publication in this journal is cited, in accordance with accepted academic practice. No use, distribution or reproduction is permitted which does not comply with these terms. 